\title{
SURGICAL CORRECTION OF COARCTATION OF THE AORTA BY AN "ISTHMUSPLASTIC" OPERATION
}

\author{
BY \\ K. VOSSSCHULTE \\ From the University Surgical Clinic, Giessen/Lahn, Germany
}

(RECEIVED FOR PUBLICATION JUNE 5, 1961)

Crafoord and Nylin in 1945 introduced a surgical method of treatment of coarctation of the aorta which in a short period of time was shown to be very successful. Their method of resection with end-to-end anastomosis of the aorta is to-day widely practised throughout the world and experience has proved everywhere the correctness of the therapeutic concept.

Since the haemodynamic disturbances in coarctation of the aorta have mechanical causes, the surgical aim does not require discussion. The main goal is complete elimination of the narrowing and restoration of the uniformity of the circumference of the aorta with enlargement of its lumen at the coarctation to the diameter of the proximal part. As stated by Schad, Bettex, Kolb, Bühlmann, and Grob (1958) and by Karnell (1959), only when this goal has been achieved by surgical means will the haemodynamic results be satisfactory.

Technical problems arise mainly when the stenosis is long. Resection with end-to-end anastomosis easily leads to compromise. In such cases the surgeon, with end-to-end suture in mind, exercises the utmost caution and sacrifices no more than is absolutely necessary, but this can easily result in post-operative stenosis at the suture line. In favourable anatomical circumstances, to turn down the divided left subclavian artery as proposed by Blalock and Park (1944) and by Clagett (1948) provides a useful expedient. Unfortunately, however, the danger of angulating the vessel considerably restricts the use of this method. Therefore, in cases of long coarctation, the use of preserved aortic grafts, according to the proposal of Gross (1951), has acquired many adherents, even though it is a somewhat complicated procedure and requires two circular sutures. In atypical cases the use of a vascular prosthesis also allows repair by bypass as lately demonstrated by Morris, Cooley, DeBakey, and Crawford (1960).
Bernhard (1949) and Walker and Haxton (1954) have proposed a method of avoiding a circular resection by making an oval or wedge-shaped excision of the vessel wall to enlarge the lumen. We have devised a method which would ensure preservation of all the available material of the vessel without resection when the vessel is enlarged. Senning (1959) reported recently that these concepts had been applied in operations on patients with abdominal coarctation, and we described this method of treatment for the thoracic aorta in 1957 on the basis of our earliest cases, calling it the "isthmusplastic" operation (Vossschulte, 1957). Since then our experience has increased and now ensures a more competent judgment concerning the efficiency of the method.

\section{METHOD}

There are two variants of the surgical procedure for coarctation of the thoracic aorta situated in the typical position :

(1) The "direct isthmusplastic" operation for a short stenosis is shown in Fig. 1. The narrowed aorta is incised longitudinally and sutured transversely, the extent of the incision proximally and distally determining the size of the lumen. When the stenosis is short, a full diameter must always be achieved. In $\frac{7}{2}$ the direct isthmusplastic operation we use interrupted everting sutures.

(2) The "indirect isthmusplastic" operation is N accomplished by means of a lateral patch after $N$ longitudinal incision of the entire stenosis. When the $\omega$ stenosis is long, starting at the origin of the subclavian artery, the incision has to be lengthened into the 6 subclavian artery (Fig. 2). It is essential that the incision be extended far enough in cranial and caudal $\stackrel{\odot}{+}$ directions to obtain a uniform circumference of the $T$ vessel. In the past we used a homograft for the patch ; but recently only dacron. The size and form $\overrightarrow{\mathbb{D}}$ of the patch can be adjusted individually during the $\frac{O}{\mathbb{P}}$ operation as required. We use a continuous everting suture for fixing the patch. 


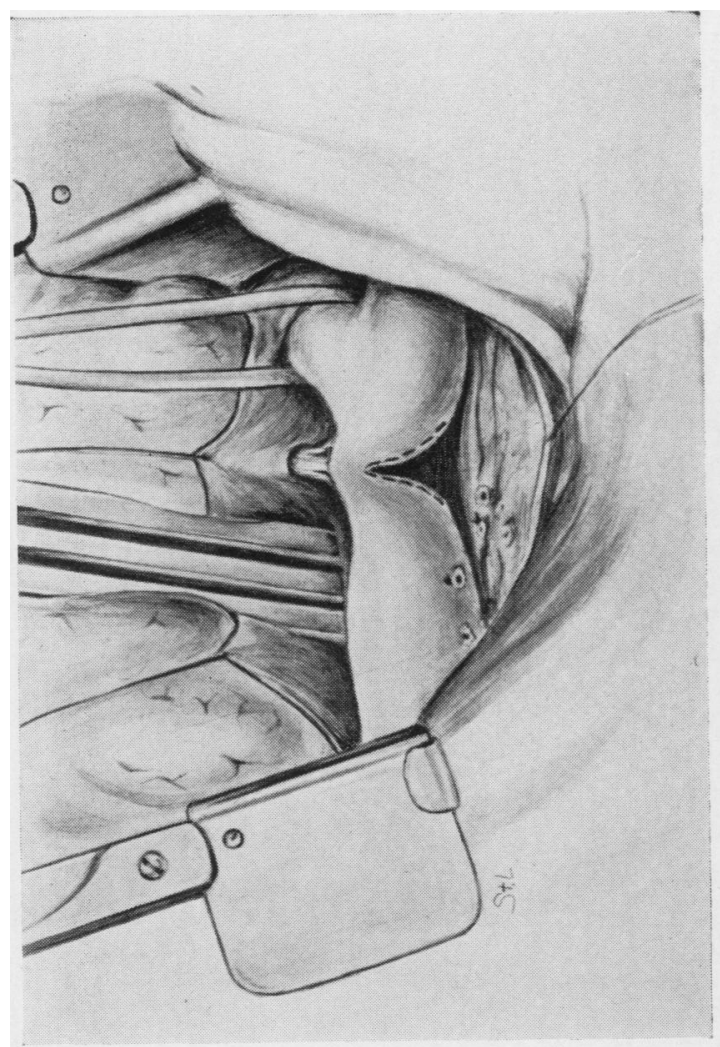

FIG, 1 (a)

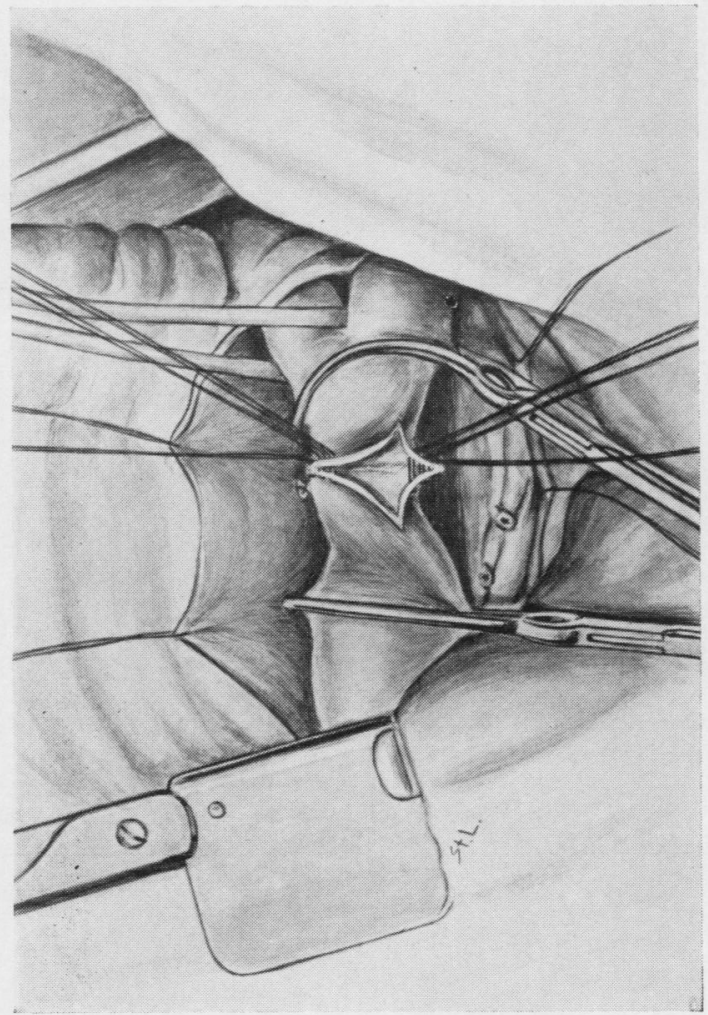

FIG. 1 (b)

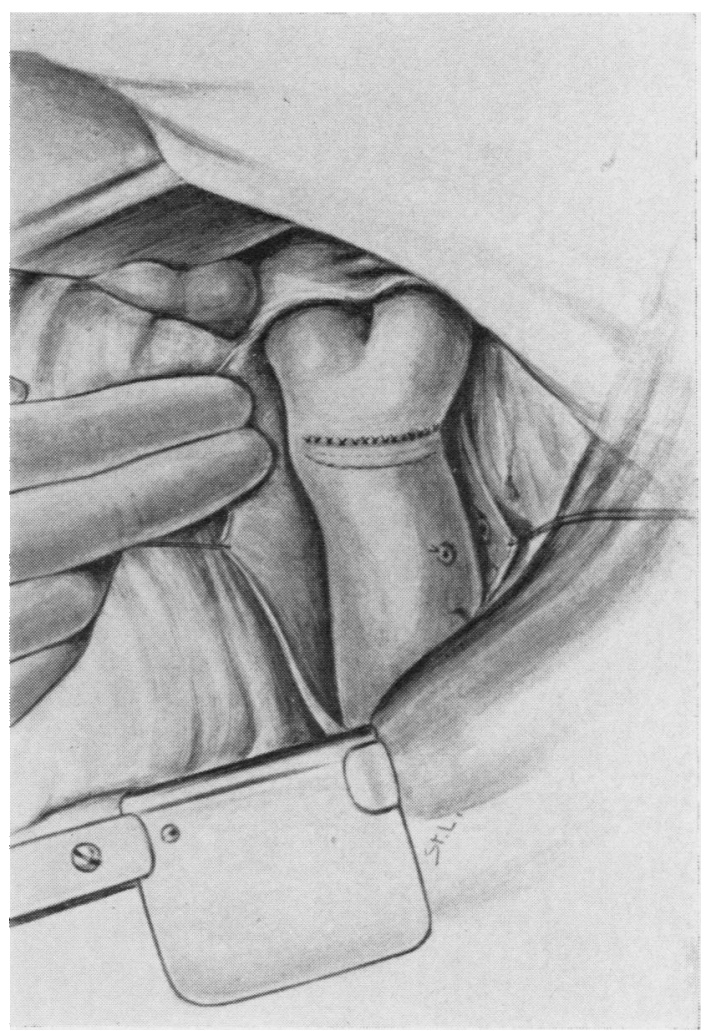

FIG. 1 (c)

FIG. 1.-Technique of the direct isthmusplastic operation. (a) Line in of the longitudinal incision of the aorta. (b) Beginning of the transverse suture. (c) Completed suture. 

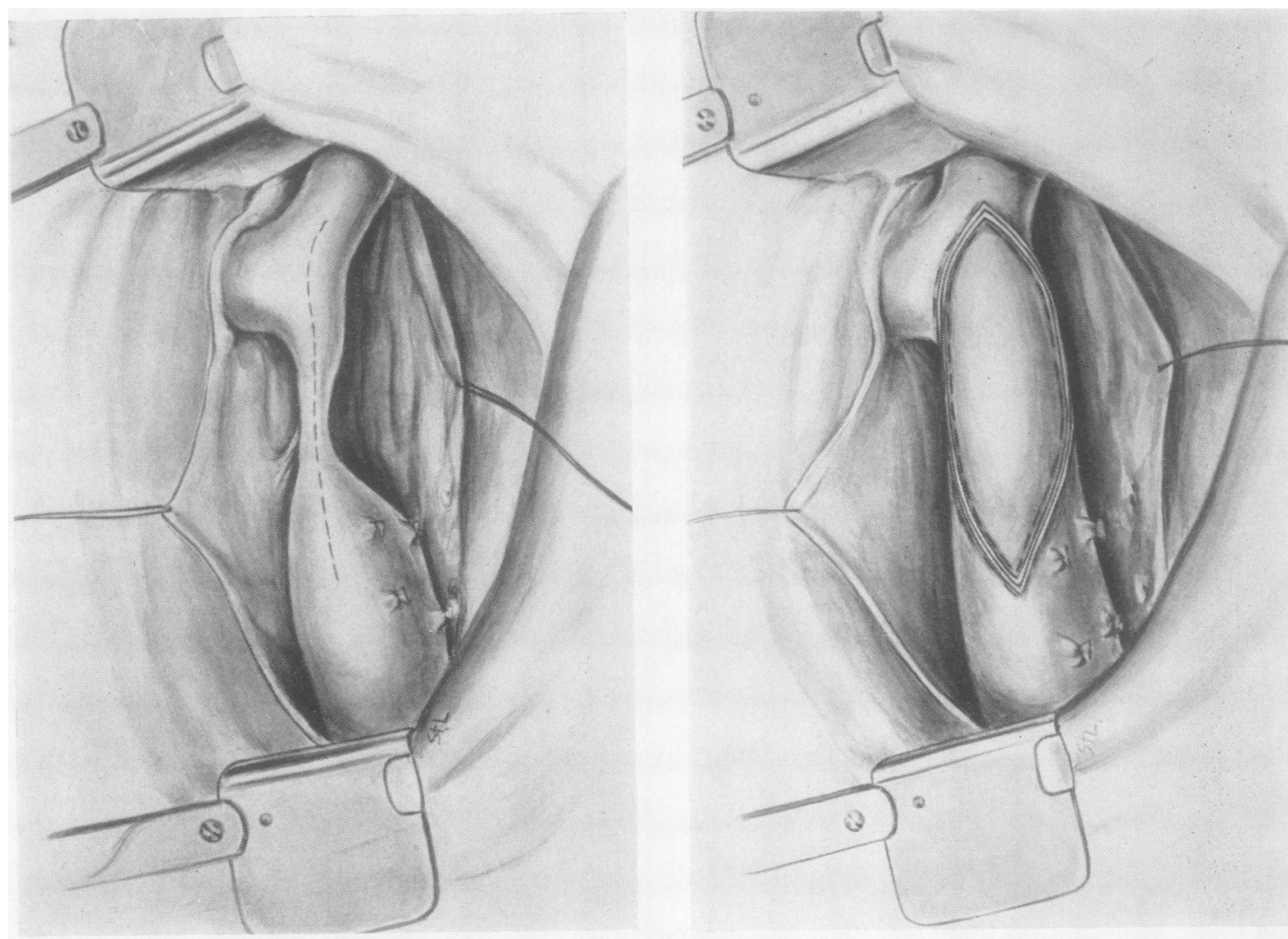

FIG. $2(a)$

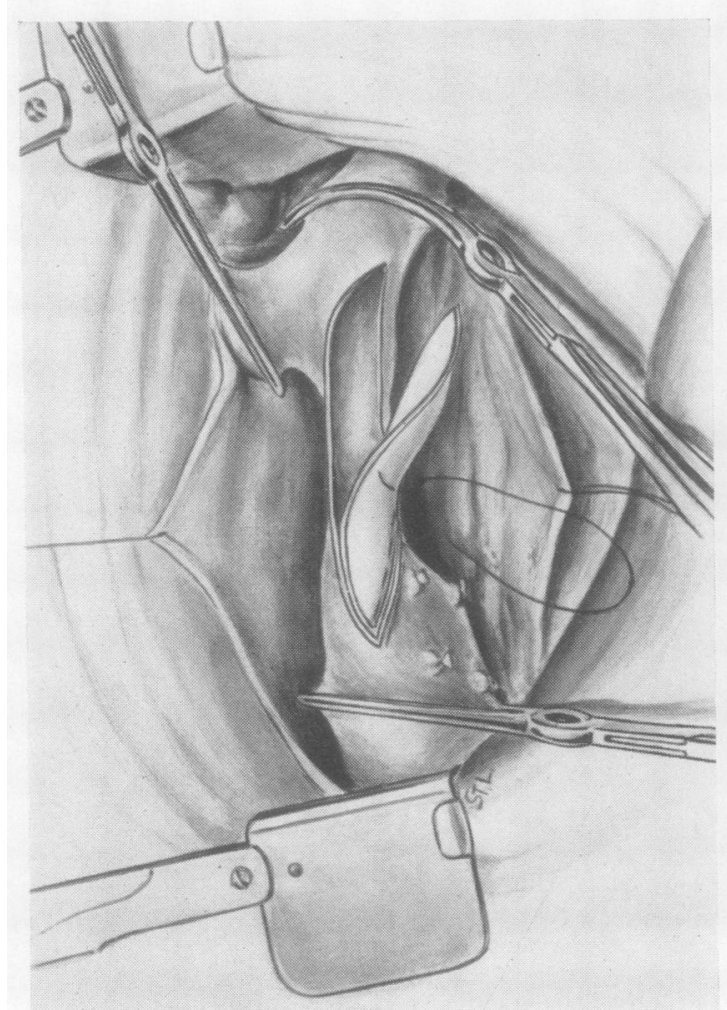

FIG. 2 (c)

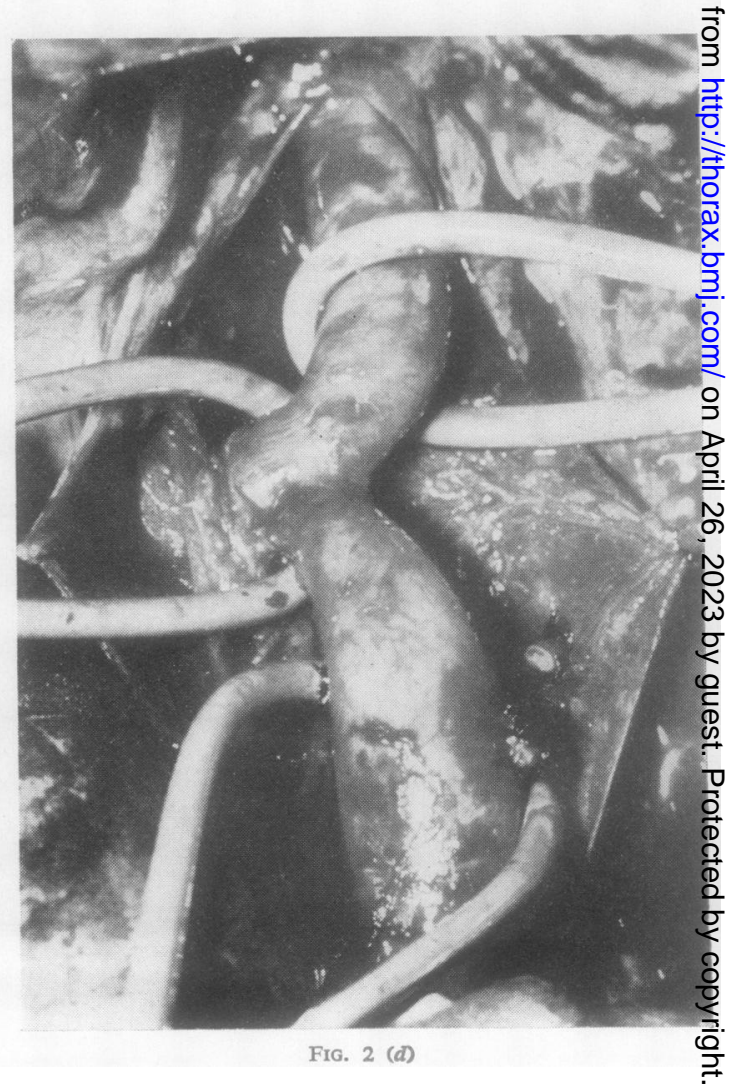




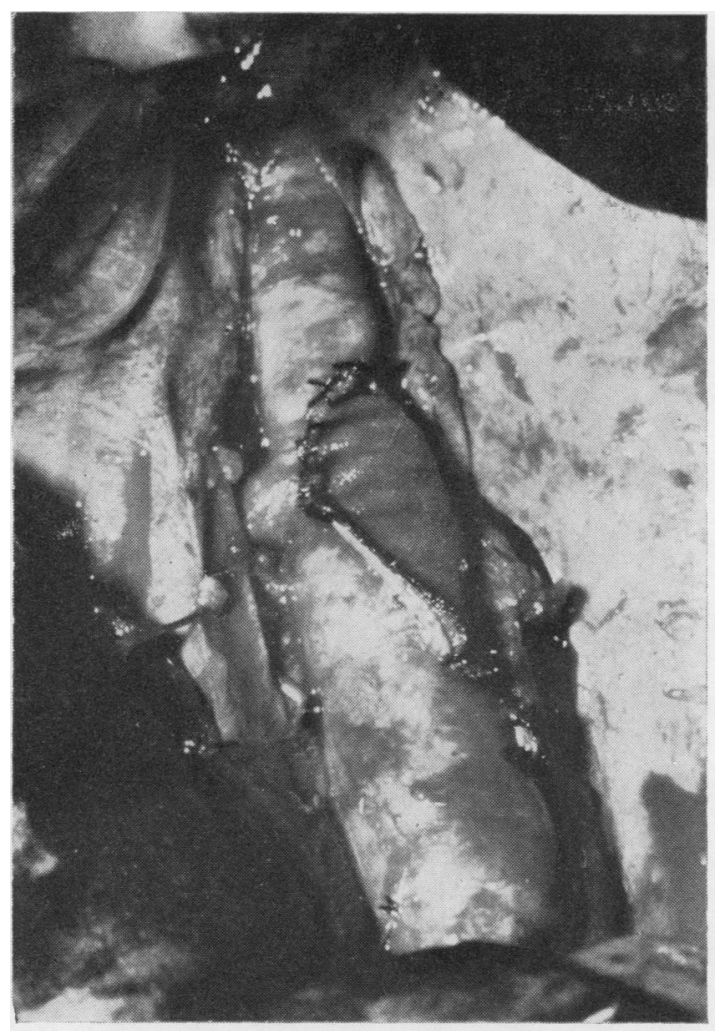

FIG. $2(e)$

FIG. 2.-Technique of the indirect isthmusplastic operation (a) Longitudinal incision up to the left subclavian artery. (b) Insertion of lateral patch. (c) Normal dimensions of aorta after completion of the isthmusplastic operation. $(d, e)$ Operative field illustrating a teflon patch inserted up to the subclavian artery.

The isthmusplastic operation provides some advantages that simplify the surgical technique and ensure a safe and successful result:

(1) The limited mobilization of the vessel shortens the preparation. Often it can be achieved by the division of only one pair of intercostal vessels.

(2) Since a circular suture is avoided in all cases, re-stenosis due to later shrinkage of the scar is not to be feared ; furthermore there is a possibility of growth if the operation is performed during infancy.

(3) Since only readily accessible parts of the vessel wall are required for suturing, the performance of the suture is simple.

(4) The isthmusplastic operation with its two variants can be performed for all typical coarctations, irrespective of form. In all cases an enlargement of the vessel diameter has to be effected. If necessary, adjustment is possible by lengthening the incision during the suturing of the vessel.

(5) The indirect isthmusplastic operation is also possible when the aorta is atheromatous, because a broader lip can be taken by the suture without a risk

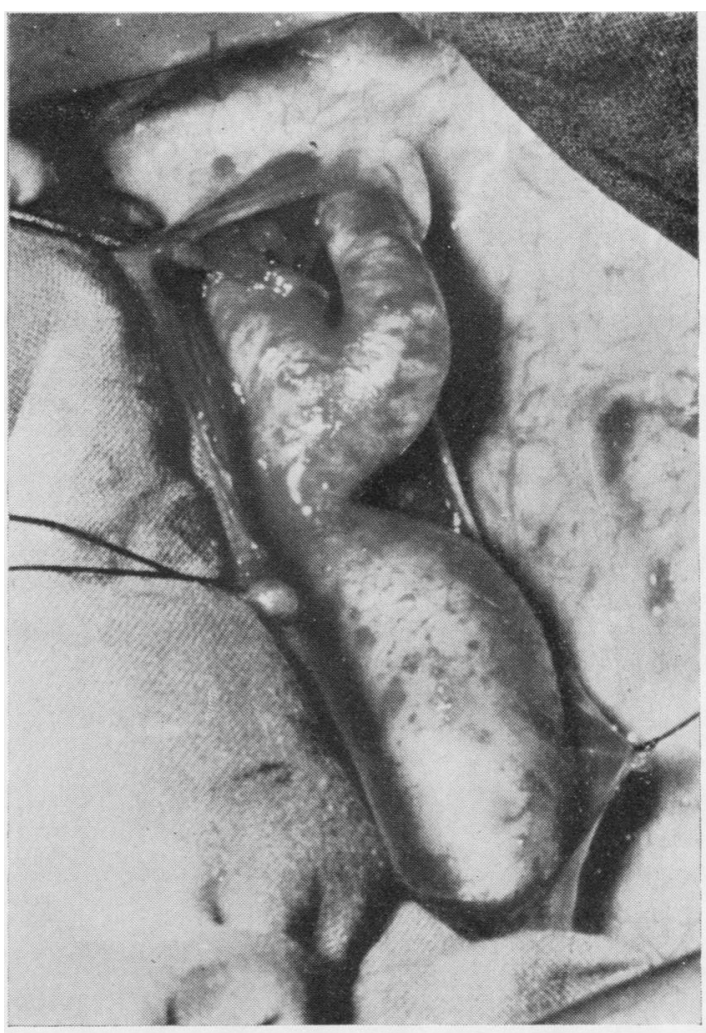

FIG. $3(a)$

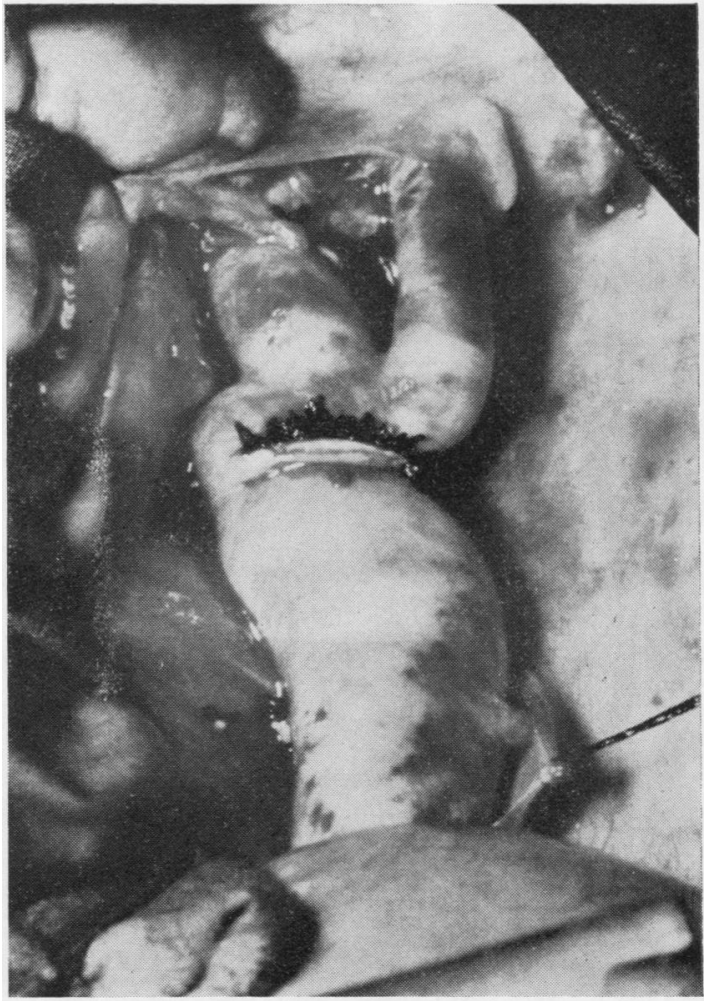

FIG. 3 (b)

FIG. 3.-Case 1. (a) Coarctation, operative appearance. (b) Appearance after completed isthmusplastic operation. 
TABLE I

DATA OF BLOOD PRESSURE RECORDED IN THE FIRST SERIES OF ISTHMUSPLASTIC OPERATIONS. OPERATIVE PROCEDURE AND TYPE OF PATCH USED ARE NOTED

$\begin{array}{llllllll}\text { NAME } & \text { K.H. } & \text { R.K. } & \text { H.J. } & \text { SCh.F. } & \text { B.K. } & \text { O.H. } & \text { R.Chr. } \\ \text { AGE ISEX } & 15 \mathrm{M} & 66 \mathrm{M} & 19 . F & 30 . M & 15 \mathrm{M} & \text { O M } & 12 F \\ \text { OP. } & \text { DIR. } & \text { HOM. } & \text { DIR. } & \text { HOM. } & \text { HOM. } & \text { DIR. } & \text { DIR. }\end{array}$

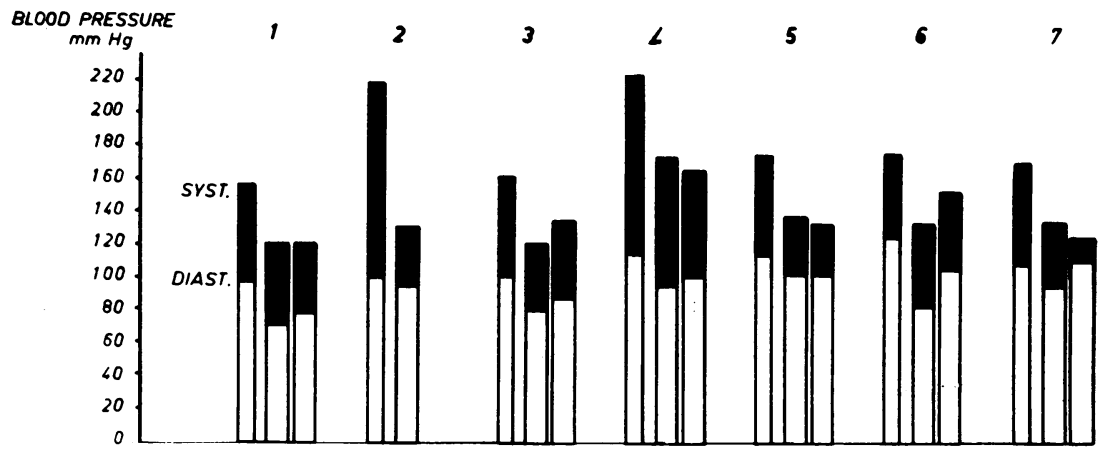

$\begin{array}{lccccccc}\text { NAME } & \text { B.H. } & \text { F.G. } & \text { N.J. } & \text { K.A. } & \text { C.W. } & \text { W.L. } & \text { P.W. } \\ \text { AGE/SEX } & 29 M & 21 M & 25 M & 20 M & 26 M & 42 F & 61 / 2 M \\ \text { OP } & \text { DACRON } & \text { DACRON } & \text { DIR. } & \text { DACRON } & \text { DIR. } & \text { DACRON } & \text { DIR. }\end{array}$

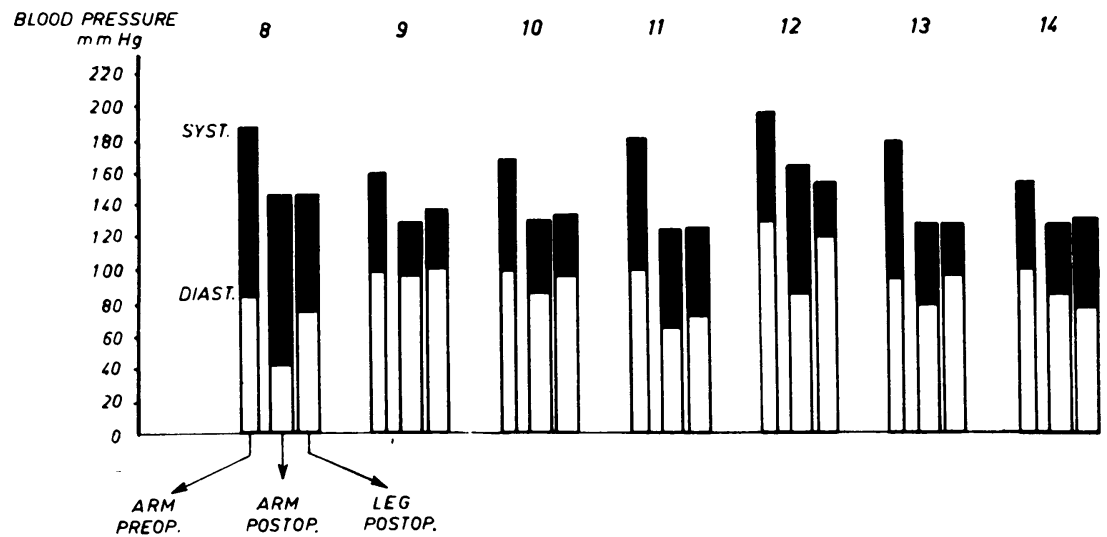

of narrowing, and the suture is not under longitudinal tension. According to our experience atheromatous degeneration and calcification occur only relatively late in life (beyond the age of 30 to 35 years).

The following cases demonstrate the efficiency of the isthmusplastic operation.

CASE 1.--P. W., $4 \frac{1}{2}$ years of age, was transferred from the Kerckhoff-Klinik, Bad-Neuheim, to our clinic on May 25, 1960, with the diagnosis of coarctation. A blood pressure of $150 / 100 \mathrm{~mm}$. $\mathrm{Hg}$ was registered in both arms, whereas the pulses in the femoral and dorsalis pedis arteries were absent and no oscillation could be found by oscillographic examination of the legs. The child often suffered from pneumonia and chronic bronchitis. Since his development was considerably below average surgical intervention was advised.

On January 6, 1960, a direct isthmusplastic operation was performed.

Fig. 3a illustrates the operative field after mobilization and Fig. $3 \mathrm{~b}$ shows the extent of enlargement achieved by the plastic method. Post-operative blood pressure is shown in Table I (No. 14). The child was discharged on June 25,1960 . Since that time pneumonia has not recurred, growth is normal, and development has considerably improved. There are strong pulses in both feet.

CASE 2.-M.K., a man of 19 years of age, complained of occasional headache during the earlier 

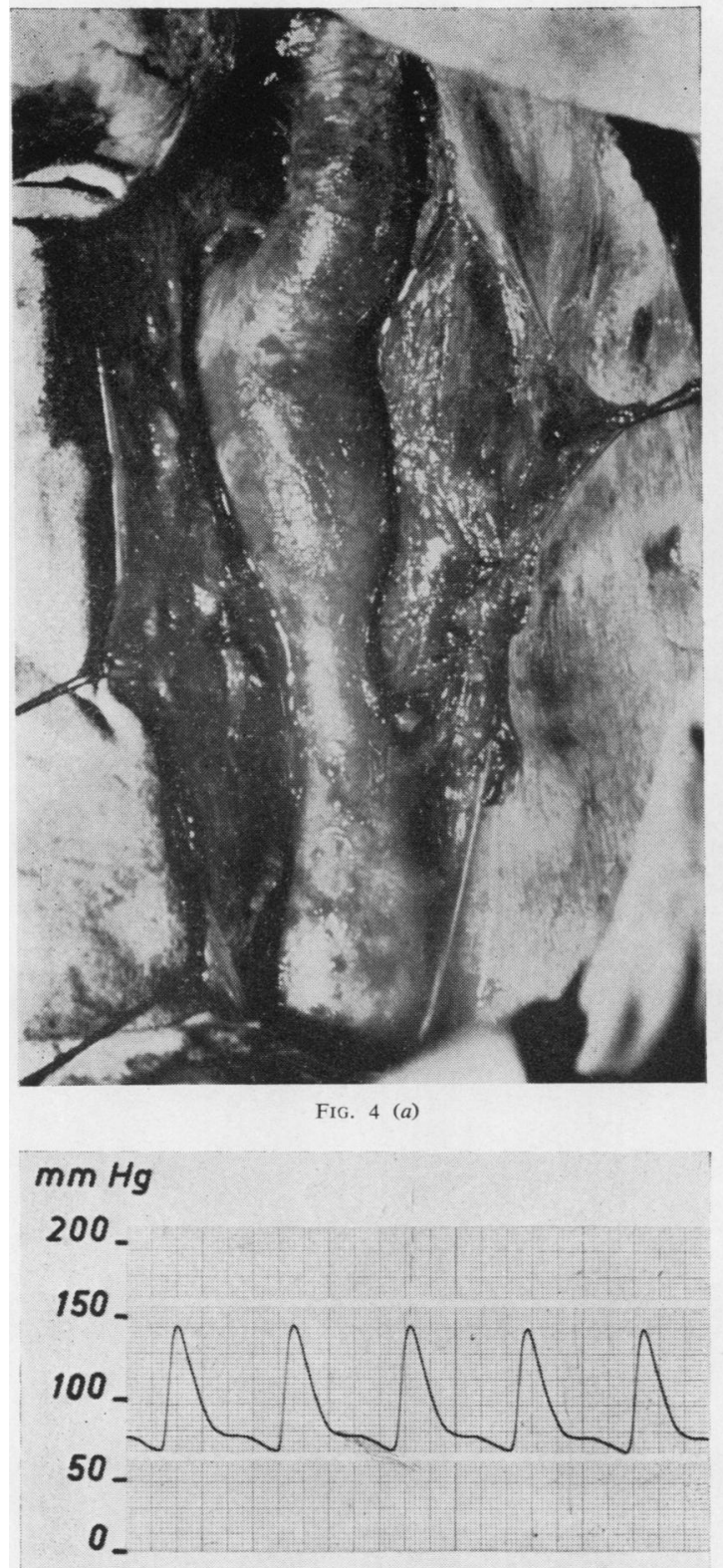

Art. radialis

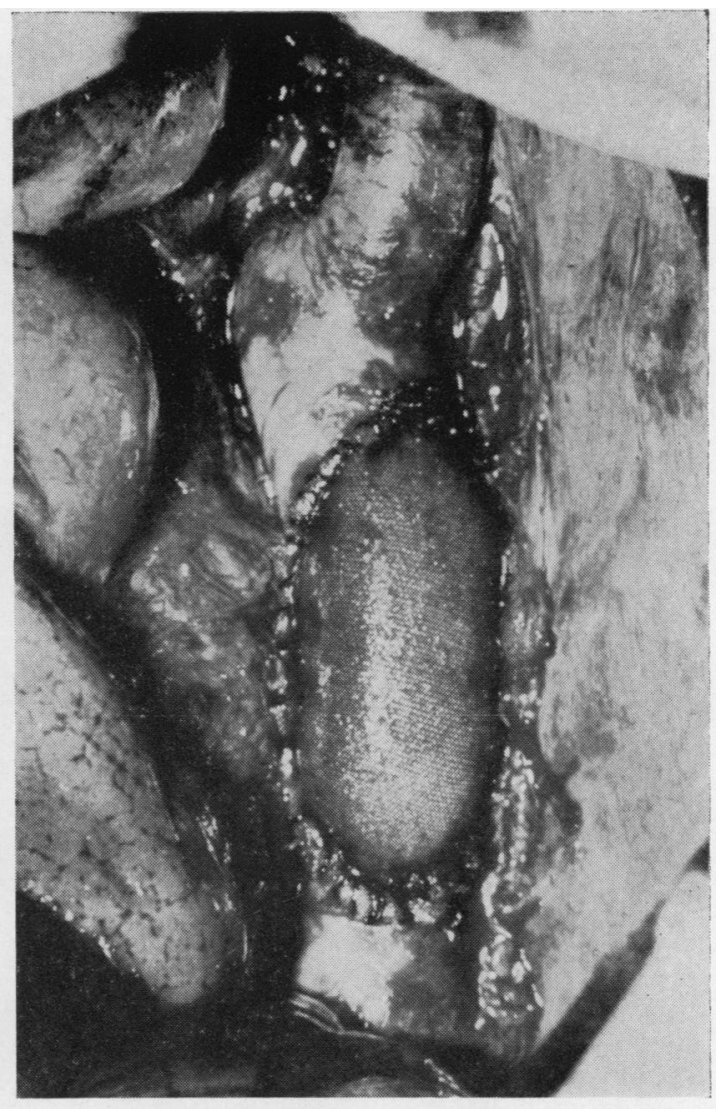

FIG. $4(b)$

\section{$\mathrm{mm} \mathrm{Hg}$}

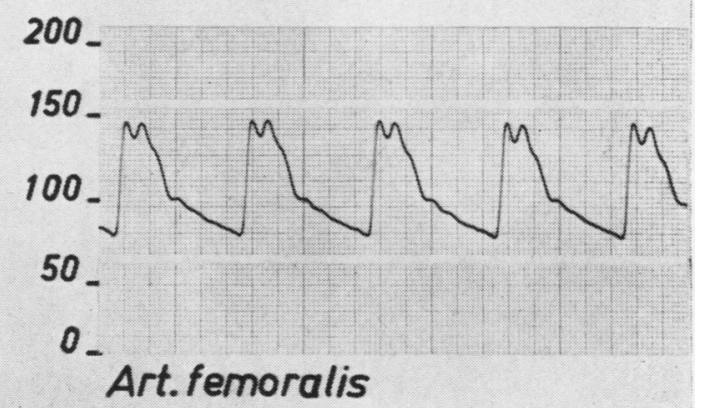

FIG. $4(c)$

FIG. 4.-Case 2. (a) Coarctation in situ. (b) After indirect isthmusplastic operation by means of a lateral graft. (c) Direct recording of pressure in radial and fenoral arteries two months after operation.

school years, becoming worse during his apprenticeship. Recently attacks of dizziness have occurred more frequently. At a routine examination, three months ago, a blood pressure of $250 / 50 \mathrm{~mm}$. $\mathrm{Hg}$ was found in the arms. A femoral pulse was not found on either side. Fig. $4 \mathrm{a}$ shows the stenosis before and Fig. 4b after the indirect isthmusplastic operation. In this case the blood pressure was measured directly and found to be the same in the radial and femoral arteries (Fig. 4c). He has returned to work as a joiner.

CASE 3.-N.J., a man of 25 years of age, complained of increasing heart trouble with palpitation and anxiety. Because of mental depression he was examined in a neurological clinic, where the diagnosis of coarctation was made. 

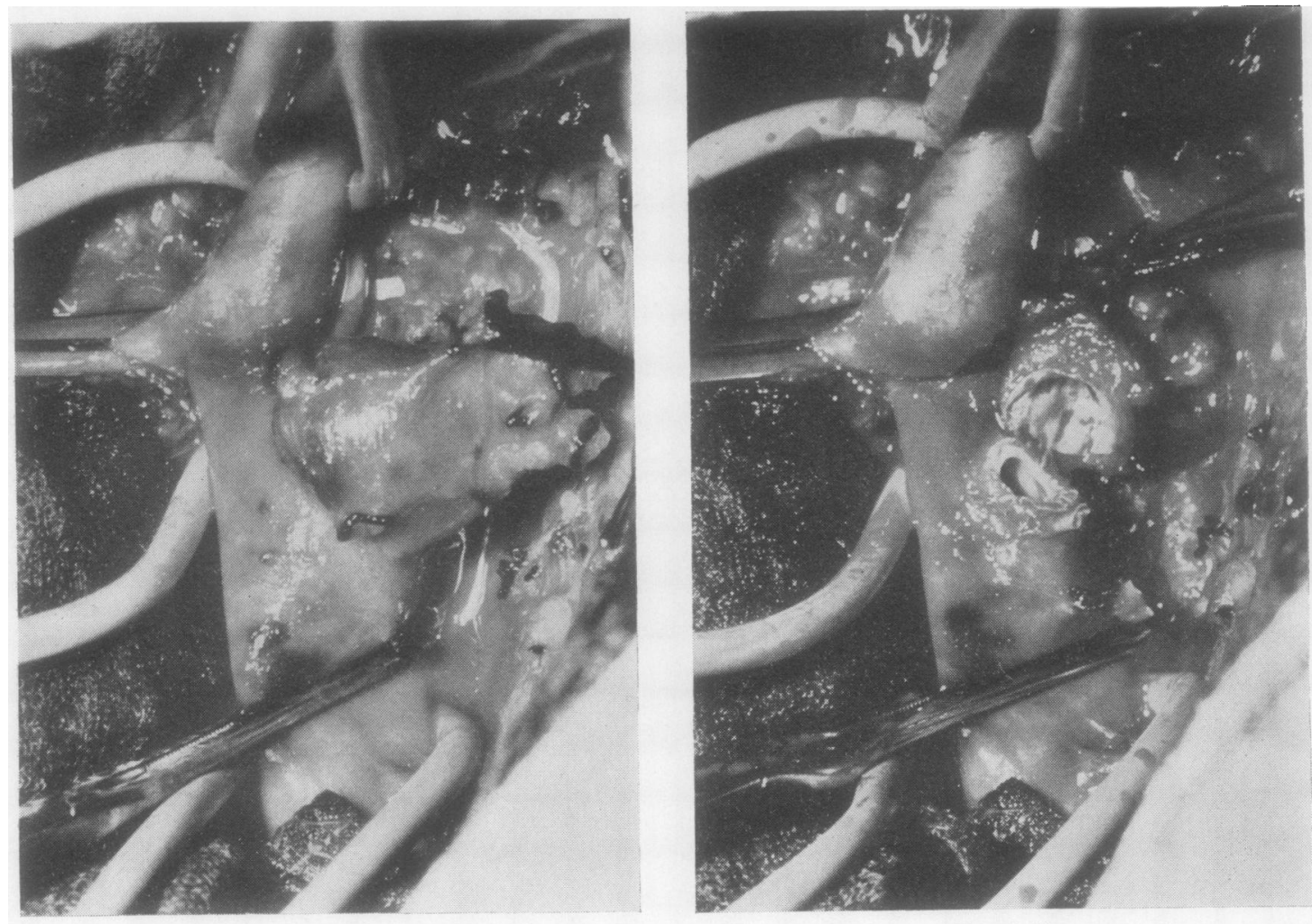

FIG. $5(a)$
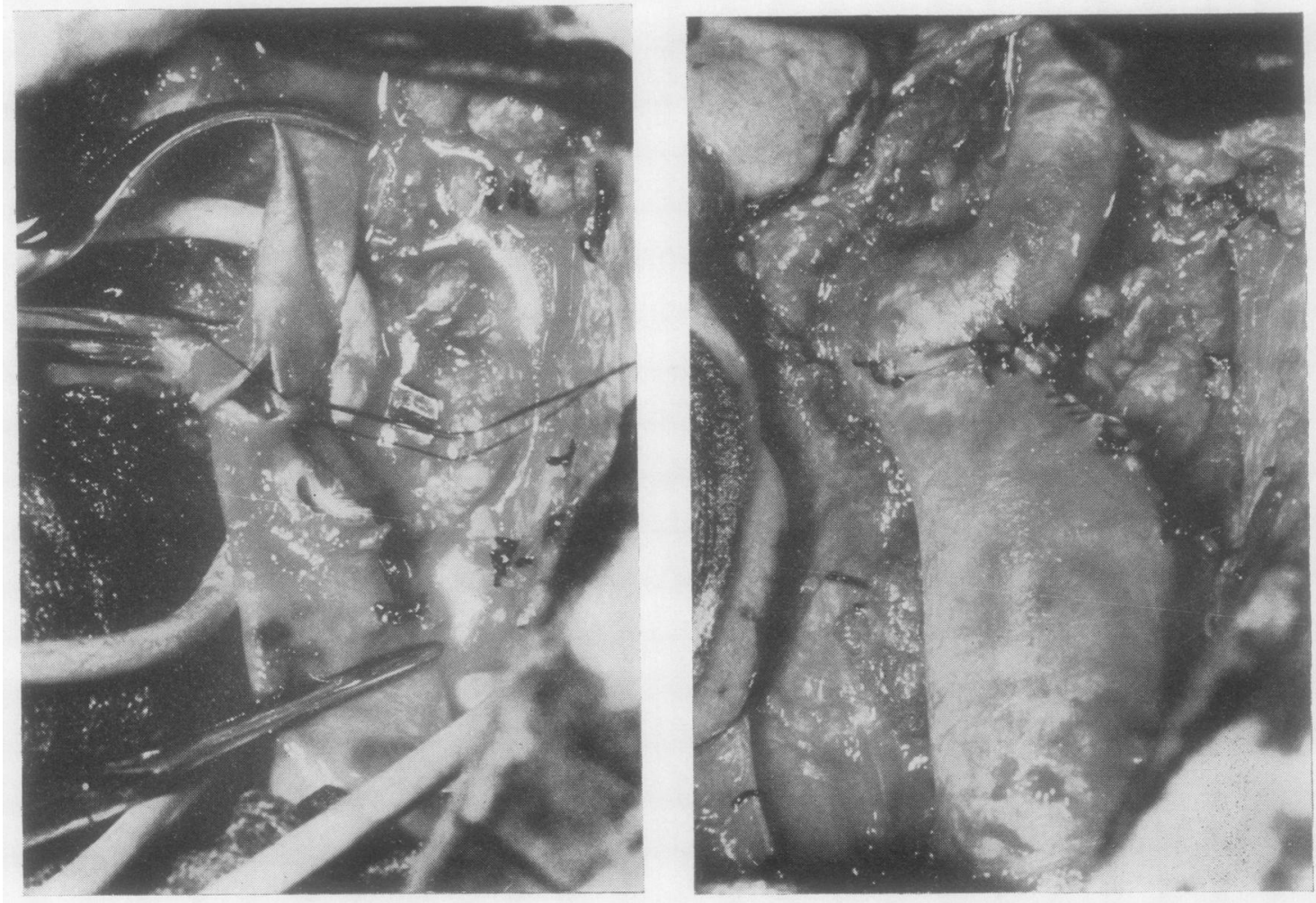

FIG, $5(d)$

FIG. 5.-Case 3. (a) Coarctation with large aneurysm. (b) Excision of the aneurysm. (c) Start of the suture for the direct isthmusplastic operation. (d) Final appearance with longitudinal occlusion of the aneurysmal opening into the aorta. 
On admission, on November 11, 1959, we observed strong pulsation in the neck. Over the entire precordium a systolic murmur was audible. The murmur could also be detected on the left side of the back. The blood pressure was $175 / 85 \mathrm{~mm}$. $\mathrm{Hg}$ in both arms. Femoral pulses were absent and the lower extremities were underdeveloped.

On December 4, 1959, an isthmusplastic operation was performed. Fig. 5a shows the operative appearance. There was a large aneurysm, which was isolated, together with the intercostal artery originating at the same level. After clamping the aorta, the aneurysm was excised at its base (Fig. 5b). A direct isthmusplastic operation was accomplished (Fig. 5c). The result of the operation is shown in Fig. 5d. The post-operative course was uneventful. The blood pressure data obtained are shown in Table I (No. 10). The pulses in the legs were strong on both sides.

The patient was discharged on February 4, 1960. $\mathrm{He}$ is now working as a mechanic and has no complaints.

\section{Discussion}

From our first series of 14 patients a 46-yearold man died four days after operation due to cerebral softening of the right hemisphere (Table I, No. 2). A homograft was used. In this case the drastic fall of the blood pressure from 210/100 to $130 / 90 \mathrm{~mm}$. $\mathrm{Hg}$ obtained by the isthmusplastic operation resulted in a diminished circulation in the brain and caused death. Groves and Effler (1960) made a similar observation.

The lowering of the blood pressure in the upper extremities is considered the most important clinical criterion of the results obtained. It is required that the systolic and diastolic blood pressures of the lower and upper extremities correspond within their physiological variations. This was obtained within 48 hours after the operation in all cases where the isthmusplastic operation was used. Post-operative abdominal pain was not observed. It cannot be explained why in some cases hypertension remains despite the same blood pressure in lower and upper extremities (Table I, Nos. $4,8,12)$. The theories discussed so far are not sufficient. Certainly we are not dealing with a Goldblatt effect.

A careful follow-up done by Stiller (1961) has revealed that good results persist among our patients. Our experience with the isthmusplastic operation is so favourable that we consider it the procedure of choice.

\section{SumMary AND CONCLUSIONS}

Direct and indirect isthmusplastic operations can be performed for coarctations below the origin of the left subclavian artery. The surgical technique is easy; the method is always the same and can be employed for any form and extent of coarctation. In all cases the vessel can be enlarged to the diameter required. The procedure does not leave any tendency to re-stenosis. For this reason the post-operative results, including the haemodynamic changes, are very satisfactory.

\section{REFERENCES}

Bernhard, F. (1949). Chirurg, $20,145$.

Blalock, A., and Park, E. A. (1944). Ann. Surg., 119, 445.

Clagett, O. T. (1948). Proc. Mayo Clin., 23, 359.

Crafoord, C., and Nylin, G. (1945). J. thorac. Surg., 14, 347.

Gross, R. E. (1951). Ann. Surg., 134, 753.

Groves, L. K., and Effler, D. B. (1960). J. thor. cardiovasc. Surg., 39,60 .

Karnell, J. (1959). Opusc. med. (Stockh.), Suppl. 1.

Morris, G. C., Cooley, D. A., DeBakey, M. E., and Crawford, E. S. (1960). J. thor. cardiovasc. Surg., 40, 705.

Schad, N., Bettex, M., Kolb, E., Bühlmann, A., and Grob, M. (1958). Helv. paediat. Acta, 13, 505.

Senning, A. (1959). Acta chir. scand., 118, 81.

Stiller, H. (1961). Dtsch. med. Wschr., 86, 72.

Vossschulte, K. (1957). Thoraxchirurgie, 4, 443.

Walker, R. M., and Haxton, H. (1954). Brit. J. Surg., 42, 26. 